\title{
LA EDUCACIÓN SE INCRUSTÓ EN EL PROCESO EVOLUTIVO Y FLORECIERON LOS HUMANOS
}

\author{
Education incorporated in the evolutionary process \\ and humans blossomed
}

\author{
Joaquín GARCÍA CARRASCO* y Macarena DONOSO GONZÁLEZ*** \\ *Universidad de Salamanca. España. \\ carrasco@usal.es \\ bttps://orcid.org/0000-0001-7809-8405 \\ **niversidad Antonio de Nebrija. España. \\ mdonoso@nebrija.es
}

bttps://orcid.org/0000-0003-0662-2508

Fecha de recepción: 06/04/2020

Fecha de aceptación: 30/08/2020

Fecha de publicación en línea: 01/11/2020

Cómo citar este artículo: García Carrasco, J. y Donoso González, M. (2021). La educación se incrustó en el proceso evolutivo y florecieron los humanos. Teoría de la Educación. Revista Interuniversitaria, 33(1), 133-151. https://doi.org/10.14201/teri.22824

\section{RESUMEN}

Introducción: el horizonte de nuestro tema relaciona la evolución humana y la acción educativa. Hipótesis: educación es un término prácticamente ausente en los escritos de paleoantropología. Sin embargo, hoy hay programas de investigación donde la cultura adquirió la categoría de motor de la evolución humana. El término cultura esconde que la mediación y cooperación intersubjetiva — que conforman la enseñanza- son los mecanismos principales de la cultura acumulativa. La cultura caracterizó el género Homo, dentro del cual evolucionó Homo sapiens; el escenario de esa cooperación cultural es precisamente el motor social del proceso educativo. Procedimiento: para el argumento utilizaremos argumentos de la paleoantropología y nos uniremos a los puntos de vista más recientes, proponiendo educación como concepto para identificar el mecanismo fundamental de los procesos culturales.

Palabras clave: evolución; cultura acumulativa; cooperación; crianza; educación. 


\section{ABSTRACT}

Introduction: the horizon of our topic, relates human evolution and educational action. Hypothesis: education is a practically absent term in paleoanthropology writings. Nonetheless, today there are research programs where culture acquire the category of engine of human evolution. The term culture hides that mediation and intersubjective cooperation — both of which conform teaching - are the main mechanisms of cumulative culture. This characterised the genus Homo, within which Homo sapiens evolved; that cultural cooperation is precisely the social engine of the educational process. Procedure: we will use paleoanthropology discoveries for the reasoning and we will join the most recent points of view, proposing education as a name for identification of the fundamental cultural processes.

Key words: evolution; cumulative culture; cooperation; upbringing; education.

\section{INTRODUCCIÓN}

Al elegir un tema de investigación, anunciamos un proyecto que puede afectar puntos de vista o ideas clave, o distorsionar la cartografía consensuada de un dominio de conocimiento; alivia entonces comprobar que existan otros autores que participen de la perspectiva.

Muchos científicos de la evolución humana, en la actualidad, ponen su foco de atención en la cuestión de las prácticas culturales; según Williams, "Cultura es una de las dos o tres palabras más complicadas en lengua inglesa»; porque su significado ha sufrido un convulso desarrollo histórico, se ha incrustado como concepto clave en "disciplinas intelectuales diferentes», incluso dentro de "sistemas de pensamiento incompatibles». (2003, p. 87, cursiva del original). El significado de la palabra ha sufrido la presión de, al menos, dos tendencias desquiciantes: a la colmatación y al vaciado; a la primera contribuyeron las definiciones descriptivas, ejemplo Tylor (1977), que tanto se han multiplicado; a la segunda, quienes la reducen a una abstracta transferencia de información, ejemplo Mosterín (2009); a sabiendas de que por información se entiende desde Shannon (1948), un concepto puramente formal. Durante ese tiempo, sin embargo, dentro de la corriente central de la antropología, quedaron marginados términos de origen más reciente como educación y pedagogía, con indudable relevancia cultural.

Lerena (1940-1988), sociólogo y economista, llegó a afirmar que educación no es un concepto, sino un precepto (1983); otros, con peor criterio, el ritual de un culto (Sánchez Tortosa, 2018). Muchos autores proponen construir la pedagogía, el campo de la educación, sobre cimientos de la psicología y de la ética (Herbart, 1983), por no vislumbrar cimiento propio.

Gracias al criterio de dos estudiosas, discípulas de Boas (1858-1942), Benedict (1887-1948) y Mead (1901-1978) (Rodríguez y Campos, 2010), el término educación adquirió relevancia dentro de la Antropología. Ellas propusieron investigar el 
nexo entre "cultura y personalidad»: asumían el criterio de que la cultura modula y consolida la personalidad de la gente y la "personalidad básica" de la comunidad, término acuñado por Kardiner (1955).

No conviene olvidar que "cultura" es el término primitivo o prístino, desde Cicerón y Virgilio (García-Carrasco, 2007), para nombrar el cultivo y el cuidado de las crías humanas; en definitiva, el proceso extragenético (como gustan decir algunos paleoantropólogos) intersubjetivo con el que se promueve intencionalmente entre seres humanos el desarrollo potencial de competencias mentales y prácticas; su metafórica se extraía de los cultivos del campo. Nuestro convencimiento es que "educación» es el neologismo para referirse a sistemas de procesos que anidan en la expresión "cultura humana» (Doval, 1979), habitualmente restringida al contexto social de Homo sapiens. En todo caso, educación-cultura son términos sobre sistemas de procesos esenciales en la evolución biológica de las especies Homo. Laland, profesor de Comportamiento y Biología evolutiva en la University of St Andrews, sigue insistiendo en que $[[. .$.$] nuestra singularidad obedece a nuestra capacidad$ para imitar comportamientos con gran precisión. Ello habría iniciado un proceso de coevolución genético-cultural inexistente en otros animales». (2018, p. 12).

Laland había publicado (2017) La sinfonía inacabada de Darwin donde defendió que la emergencia y evolución de los procesos culturales estuvieron en el origen y el despliegue de las capacidades de la mente de los seres humanos. En la actualidad hay grupos de científicos cuyo programa de investigación interdisciplinar está centrado en los orígenes de la singularidad humana cultural, como proceso que se incrustó en la evolución de su estructura psicobiológica (Boyd, 2018, p. 9). En concreto, el Instituto de Orígenes Humanos (IHO) de la Universidad de Arizona; Macedo (2018, p. 11), autor del prólogo al mencionado libro de Boyd, describe así el punto de vista de este grupo:

Boyd defiende $[\ldots]$ que la cultura humana es parte del mundo natural. La cultura nos convierte en 'un tipo de animal diferente' y la cultura es parte de nuestra biología humana como lo es nuestra peculiar pelvis o el grueso esmalte que cubre nuestros molares.

Si la cultura es clave en nuestra forma de vida, lo que mejor especifica la evolución de la humanidad, la emergencia más original del proceso no está en la creación y el manejo de artefactos e instrumentos, sino en los mecanismos de la transmisión cultural; estos mecanismos forman parte primordial de la relevancia del término «educación». Las capacidades biopsicológicas que entraña la cooperación entre aprendiz y maestro, las que se ejercitan en todo escenario docente intencional, están en el núcleo original de la cultura humana, en la médula del comportamiento vital de los seres humanos, de su diferencia específica; actividad de cooperación que quedó incrustada en la evolución, beneficiando la selección natural de las especies que la practicaron. Entendemos aquí por incrustación: acoplamiento, asimilación, integración en la estructura cognitiva. Fue el punto de vista que eligieron para describir el proceso cultural-educativo Piaget, al emplear la expresión equilibración 
JOAQUÍN GARCÍA CARRASCO Y MACARENA DONOSO GONZÁLEZ

de las estructuras cognitivas en 1975 (2012), o Vygostki, refiriéndose al desarrollo de los procesos psicológicos superiores en 1978 (2012). Este es el tema en el que nos proponemos profundizar.

\section{MARCO DE REFERENCIA ONTOLÓGICA DEL TÉRMINO CULTURA}

En el campo de conocimiento antropológico, cultura, es el término de empleo más frecuente. Cualquier término, aislado el concepto que en él anida y el contexto de empleo, no puede ser ni verdadero ni falso; solo puede ser confuso o claro, fecundo o estéril, sustantivo o predicado; ejemplos, Juan tiene cultura o la cultura de los chimpancés sorprendió a los primatólogos. En el contexto de uso, el tema cultura presenta dos facies. Una como producto de la iniciativa: artefactos, instituciones, leyes, construcciones, discursos (Tylor, 1977); otra como prácticas cooperativas compartidas (Wenger, 2001). Pero, hay otra facies, con raíces muy antiguas: todas las sociedades humanas poseen como propiedad característica, la activación de procesos para transmitir sus rasgos comportamentales y sus habilidades aprendidas.

"Sociedad» es un concepto y los individuos son entes reales. La acción de transmitir, que implica los procesos de transferir, propalar y difundir, aunque fuese solo información, es aplicable con propiedad a entes reales no a conceptos. No son, por tanto, las sociedades las entidades transmisoras, sino en sentido figurado; los que transmiten, los que se comunican e interactúan, siempre son individuos, tal vez a través de instrumentos mediadores que los individuos producen. Según este criterio, la idea sociedad educadora es un concepto mal formado. Estas expresiones, que convierten significados y conceptos en sujetos de actuación, constituyen indicios de ontologías defectuosas. Sociedad es un concepto para referirse a una comunidad de individuos. Las propiedades de los individuos pueden ser primarias —objetivas o independientes del sujeto-y secundarias o fenoménicas. Todas las propiedades fenoménicas son relacionales o dependientes del sujeto; p.ej. la intensidad percibida de sonido. Es interesante distinguir en los individuos entre propiedades manifiestas y disposiciones. Las primeras se poseen por naturaleza; las segundas son propiedades que se manifiestan, si se dan las circunstancias (Mahner y Bunge, 2000, p. 21).

En los documentos, el término "cultura" se aplica de manera muy diversa: (i) para referirse a propiedades, ya sea, p.ej., calidades de artefactos o babilidades de artesanos, Ornstein (2001) pudo contar la historia de la mente humana mediante la evolución de las herramientas; (ii) para formar parte de un juicio de valor, p.ej. qué culto es; o (iii) para señalar el conjunto heterogéneo de cosas, instituciones y rasgos que identifican una comunidad; por esta aplicación del término se produjo un enchimiento de significado donde se perdieron las referencias originales.

El marco de referencia que mejor plantea el significado de cultura, según la ontología que defendemos, es el de las propiedades relacionales; defendemos que la ontología particular de las interacciones de cooperación constituyó el fundamento de las propiedades específicas de los procesos de transmisión cultural, dentro del género Homo. 
La progresión argumentativa con la que el tema se explaya o expande es aquí el rema: la forma que toma el discurso. El hecho de que «educación» (procesos relacionales con intencionalidad formativa) identifique el tema de estudio en el dominio de la Pedagogía, incluso promoviendo referencia expresa a un sistema de valores, en tanto que en el resto de la Humanidades predomine el de "cultura" (con referencias objetivas a la producción), puede ser una fuente de incomprensión sobre la centralidad antropológica del discurso pedagógico. No obstante, el término latino cultura, situó en el primer plano de esa significación la cooperación social, especialmente la acogida incondicional y la intencionalidad cuidadora de la familia, característica de la crianza.

En la especie humana, las acciones y procesos de crianza, educacionales, los mecanismos o las funciones mentales que se activan en la transmisión de cultura, componen una parte principal de la vida cotidiana. Para esa forma de vida, no es guía realista la teoría de la elección racional, ni el marco tecnológico: la mayor parte de los sucesos no son aleatorios, la mayoría de los problemas de la vida cotidiana se resuelven siguiendo reglas "listas para usar", sin recurrir a sofisticados cálculos; los actores de la vida real raramente son libres y nunca son omniscientes; y las personas normales están constreñidas por las normas sociales y morales. (Bunge, 2006, p. 378). Esto no se puede olvidar al construir una antropología de la educación.

En lo que sigue, no pretendemos discutir cuestiones que debaten los paleoantropólogos o los especialistas en prehistoria humana; admiramos sus trabajos y consideramos sus conclusiones mejor probadas, imprescindibles para una antropología cultural y de la educación. Sí nos parece advertir que crece el interés por considerar los procesos de cooperación, como inductores necesarios de la evolución cognitiva en la filogenia humana, especialmente los que denominados mecanismos de transmisión cultural, aunque los fósiles únicamente sugieran indicios. Una situación en la filogenia humana, donde esos mecanismos tuvieron que actuar, de manera evidente y en forma directa, es la crianza. Si esa situación, aunque no deja evidencia fósil, adquiere la relevancia merecida, cambiarían algunos aspectos del "gran relato« sobre la humanización. Uno de ellos ya se está defendiendo con fuerza: el papel de la mujer, sin cuya relevancia quedaría seriamente mutilado el ramaje evolutivo de la humanidad (Aldovasio, 2008).

\section{TITUBEOS EN EL PROYECTO DE UNA ANTROPOLOGÍA CON EL CONCEPTO EDUCACIÓN (CULTURA) COMO CLAVE}

Dijimos al comienzo, que la denominación de una disciplina académica anuncia un proyecto: el propósito de embarcarse en una investigación, desde una particular perspectiva. Pensaba Montessori (1870-1952), que hacía mucho tiempo que se publicaba sobre el tema educación en perspectiva antropológica, pero que aparecía sin que el concepto de educación fuese la idea clave. La Antropología Pedagógica debía prestar atención especial, en su opinión, a «los defectos de crecimiento del hombre 
normal». (1921, p. 48); la imperfección del diseño habría de tener un puesto cardinal en ese proyecto (García Carrasco y Canal, 2018). Montessori se sintió atraída por las ideas de dos médicos franceses: Itard (1774-1838), principal estudioso de Victor del Aveyron, el calificado como enfant sauvage (niño salvaje) y E. Séguin (1812-1880), quien, animado por Itard, se había dedicado a niños con discapacidades mentales, publicando en 1846 el primer tratado sobre niños mentalmente discapacitados: "The Moral Treatment, Hygiene, and Education of Idiots and Other Backward Children". Después de esa fecha conoció la obra de Pestalozzi.

Montessori señaló un punto de vista original a la antropología pedagógica: la vulnerabilidad de la naturaleza humana, las anomalías y discapacidades que presenta, las imperfecciones congénitas y los defectos de crecimiento del ser humano normal. Este punto de vista ha sido replanteado en la actualidad por Kandel — conocido por sus hallazgos en fisiología de la memoria, Premio Nobel de Medicina en el año 2000_, quien ha publicado La nueva biología de la mente (2019); intuye que el estudio de los trastornos cerebrales contribuirá significativamente a conseguir una teoría unificada sobre la mente humana.

La mayor parte de las publicaciones sobre Antropología de la Educación señalan la fecha de 1954 como hito en la demarcación del campo: el encuentro convocado por Spindler (1920-2014) en la Universidad de Stanford y sus Actas, bajo el lema Education and Anthropology (Spindler, 1955). Colom Cañellas considera que la mayoría de edad de la Antropología de la Educación se alcanzó cuando el gran gremio de investigadores de la American Anthropology Association, en su 74 encuentro de 1975, tomó como foco de atención Hacia una definición del multiculturalismo en educación. Como primer mapa del campo de conocimiento podría considerarse la obra bibliográfica de Rosenstiel con sus 3.400 referencias bibliográficas comentadas (1977). Colom Cañellas concluye que ese listado muestra lo que fue la Antropología de la Educación en los años 80 (2005, pp. 47-48).

En el mismo capítulo, Colom abre un apartado sobre la Antropología de la Educación en sentido estricto, donde precisa que el dominio de investigación propio de la Antropología de la Educación es el de los mecanismos de la transmisión cultural, su contexto y sus mediaciones, como piensa también Robins (2003).

Hoy parece que deben participar en la construcción de la Teoría de la Educación, con notable beneficio, dos grandes elaboraciones: una, con materiales del dominio de las bioneurociencias; otra, en perspectiva evolutiva. Haciendo justicia al gigantesco esfuerzo investigador de los paleoantropólogos sobre los orígenes de la especie humana y el notable esfuerzo de divulgación del Proyecto Atapuerca en la provincia de Burgos (España).

Son muchos los científicos interesados, desde diferentes campos, en los niveles más básicos, o más primitivos, de la evolución cultural humana: ¿cómo hemos llegado a ser como somos? ¿contribuyeron de alguna manera las diferentes especies de nuestro género, con sus prácticas de cooperación, a la evolución humana? 
La historia evolutiva dejó huellas que han quedado inscritas en los diferentes niveles de nuestra organización biológica, en la unidad psicosomática que nos constituye. En el marco de la evolución de la estructura sistémica es donde, en nuestra opinión, encontraremos la verdadera relevancia de significado para el concepto cultura.

\section{4. ¿QUÉ PREGUNTAS JUSTIFICAN QUE LA PEDAGOGIA INDAGUE EN LAS INVESTIGACIONES SOBRE LA EVOLUCIÓN DE LAS ESPECIES HOMO?}

A Piaget le inquietaba: ¿Cómo se pasa de un estado de menor a otro de mayor conocimiento? (1986); a Carrithers: ¿Por qué los humanos tenemos culturas? (1995); al neurólogo Gazzaniga ¿Qué nos hace humanos? ¿Cuál es nuestra singularidad como especie? (2010). Arsuaga y Martín-Loeches preguntan: «Por qué somos así, tan especiales en algunos rasgos, y no de cualquier otra forma?» (2013, p. 12); las preguntas proponen identificar los rasgos que nos singularizan como especie, tanto en aspectos biológicos como en capacidades psicológicas (Mahner y Bunge, 2000, p. 124).

Para Leakey y Lewin no hay duda; en la respuesta racional a esos interrogantes está implicada la investigación sobre los orígenes evolutivos de nuestra especie (1994). Esa investigación deja al descubierto que, en ese comienzo, los procesos de ayuda mutua, cuidado, transmisión de competencias, la cultura como proceso intersubjetivo específico, la educación, en una palabra, fue profesión biológica de nuestra especie.

En la raíz de la teoría de la educación está la pregunta: ¿Por qué el ser humano necesita de la cultura para vivir, para dar de sí y no quedar en nada? (García Carrasco, 2007); sugiere hipótesis vigorosas y transiciones interdisciplinares, transgresiones de campos de conocimiento; si no lo practicamos, pueden quedar fuera del foco de atención estados de la condición humana que afectan a muchedumbres (Sánchez Ron, 2011).

En lugar de andar definiendo "cultura», poniéndole límites al término, describamos la experiencia fundamental y primaria a la que alude; las preguntas delataban un estado de necesidad, algo sin lo cual quedaría la vida de los seres humanos en precario.

\subsection{Desde Darwin, la evolución biológica es clave para una teoría de la educación}

Darwin en El origen de las especies no tenía dudas, el origen de la mente humana debía encontrarse en la evolución biológica; la mente humana habría sido fruto de una larga historia de transiciones. Por el contrario, Wallace defendía que había sido regalo divino a la humanidad. En aquel momento nadie conocía la verdadera historia. Hoy, según algunos, la mente humana emergió con nuestra especie, incluso después de llevar tiempo deambulando por este mundo. Muchos 
autores argumentan, por el contrario, que hubo procesos activos, en esa dirección, desde el comienzo de nuestra historia evolutiva.

Gould considera que el cerebro habría evolucionado por selección natural, pero la mente y el lenguaje serían exaptaciones: estructuras seleccionadas para cumplir una función que pasan de manera imprevisible a desempeñar otras (1994, p. 297, 301). Ni las capacidades cognitivas humanas ni el lenguaje ofrecen continuidades evolutivas con capacidades cognitivas o comunicacionales de otras especies anteriores. Por decirlo en términos sistémicos, en lo que a actividad mental se refiere según algunos, la especie humana (Homo sapiens) sería una emergencia ${ }^{1}$, una novedad cualitativa, sin precedentes; otras especies no serían propiamente precursoras, sino algo biopsicológicamente diferente (Gould, 2012).

Mithen (1998) y Tattersall (1998) interpretan que no se dispone de indicio alguno para presumir comportamiento consciente pleno en ninguna especie anterior a H. sapiens.

Hoy, sin embargo, cada vez son más quienes defienden la presencia de capacidades mentales humanas en especies anteriores a H. Sapiens. Los argumentos giran en torno a tres innovaciones culturales: la industria lítica, el fuego y los enterramientos (Arsuaga, 2001). En este trabajo, resaltamos la capacidad de enseñanzacultura, la cual lleva esencialmente asociado todo proceso genuino de innovación y transmisión cultural; al menos en el caso de la cultura artesana de la piedra; lo que Arsuaga califica de "El invento" (1999, p. 49). El obrador donde presumiblemente se tallaron las herramientas de piedra más sencillas, lo que implicaba alguna forma de asentamiento, podría entenderse razonablemente como un escenario de aprendices y maestros.

Los primeros fósiles atribuidos a nuestro linaje, no sin controversia, se fechan entre $7 \mathrm{ma} \mathrm{y} 4 \mathrm{ma}$. El fósil más completo que conocemos de esa época es el de una hembra llamada Ardy (Ardipithecus ramidus) (Arsuaga, 2019, p. 302). El «invento», tallar la piedra, se asocia con Homo habilis, la primera especie de homínido que construyó su nicho ecológico en paisajes abiertos de sabana, con manchas de árboles dispersos y matorrales, fuera de la selva densa de los ardipitecos y del bosque menos denso de los australopitecos. Lo fundamental fue el cambio en la manera de ganarse la vida. Para los H. habilis los recursos, en un nicho así, están más dispersos, son menos previsibles, la innovación en la dieta fue imprescindible, tuvieron que explorar y experimentar, memorizar la distribución cartográfica de las posibilidades, aprender a interpretar indicios y huellas; identificar periodicidades en el comportamiento de frutos, presas, estaciones; al reelaborar esa periodicidad en la memoria de trabajo, bien pudo derivar la expectativa y planificación a futuro en ausencia de estímulo inmediato; las dificultades que entrañaba sobrevivir en el nicho más complejo, pudieron favorecer el desarrollo de competencias de cooperación y

1. Para el análisis del concepto emergencia, véase: Bunge (2004). 
de organización social (Dunbar, 2007). En este contexto tuvo lugar «el gran invento», en expresión de Arsuaga: los primeros pasos de la elaboración de instrumentos de piedra, los primeros artefactos líticos, el inicio de la cultura de la piedra. Las tres designaciones aluden a diferentes matices en los puntos de vista. Más adelante veremos que este episodio se está anticipando en el tiempo, incluso parece que los primeros inventores son anteriores a las especies Homo.

En 1964, McLuhan publicó Comprender los medios de Comunicación. Las extensiones del ser bumano (1996). Se trataba de una teoría general en la que todo instrumento utilizado por el ser humano prolonga la actividad del cuerpo y amplifica la experiencia de los sentidos. En 1967, publicó El medio es el masaje (McLuhan y Fiore, 1969), defendiendo el criterio de que la construcción y manejo de un instrumento, cuando es fruto de un plan, incorpora a las capacidades de la mente, la inteligencia potencial del instrumento. Esta expresión también aparece en la obra de Dennett, Tipos de mentes (2000), dando a entender que el instrumento no solo prolonga, sino que puede amplificar la experiencia personal, si realmente está acoplado a planificación de la acción.

Son muchas las especies que usan instrumentos. En el caso de los chimpancés fueron muy estudiados por Sabater Pi los bastones con los que capturan las termitas (1992); constituyen una forma de cultura, en el sentido de patrón transmitido de manera extrasomática, aunque, podrían no requerir planificación. El plan implica concebir la forma y tratar de reproducirla mediante manipulación en el material. Los antropólogos consideran que únicamente tenemos evidencias de esto cuando aparecen los instrumentos de piedra. Arsuaga expone que las manos de los chimpancés no son adecuadas para la manipulación fina que exige la talla (1998, p. 132). El momento en el que tenemos evidencia del primer uso de un instrumento planificado, el grupo estaba ensayando el consumo de carne y descubre la utilidad del filo para descarnar, cortar, trocear; el bloque, para romper, aplastar, golpear huesos y obtener médulas; nos dejaría completamente seguros, si lo transportasen para la siguiente ocasión, entonces daría testimonio de una convicción de utilidad.

Los términos objeto técnico y artefacto otorgan relevancia a la intencionalidad que dirige la producción; ambos han sido tema para elucubraciones filosóficas (Simondon, 2007); pero esos discursos fueron desarrollados en el contexto de la sociedad industrial y la producción masiva de artefactos.

Consideremos, por el contrario, el escenario vital original del género humano en sus orígenes evolutivos. Tomasello (2007, p. 11) lo sintetiza diciendo:

Hace unos seis millones de años, en algún lugar de África se produjo un acontecimiento evolutivo rutinario: una población de monos antropomorfos quedó aislada, en lo que concierne a la reproducción, de los demás miembros de su especie. Este nuevo grupo evolucionó [...].

La gran odisea de la humanidad (Dunbar, 2007), ha sido reconstruida en función de varias claves. Una de ellas la sitúa en un escenario donde regía «la ley de 
JOAQUÍN GARCÍA CARRASCO Y MACARENA DONOSO GONZÁLEZ

la jungla»; Ardrey (1998) los imaginó matando para vivir, monos asesinos armados (1969). Grandes científicos han racionalizado el temperamento violento de este escenario, con «la marca de Caín» (Lorenz, 1982), la raíz de fiera que llevamos dentro (Golding, 1996); el Holocausto constituyó la prueba definitiva.

Actualmente, la investigación ha tomado otra perspectiva. Estimamos que son varios los vectores del nuevo marco de representación. (a) Tomar la naturaleza allende la ciudad, la selva en todo su esplendor, como «la naturaleza salvaje en diente y garra", que solo ofrece "amenaza", es una grave equivocación (Montagu, 1972, p. 235); este dislate es el que indujo y alimentó "el mito de la bestia» y el de los hombres fiera (bomoferus) (Bartra, 2012; 1996). (b) La realidad induce a pensar en todo lo contrario, una de las fuentes del malestar de la cultura contemporánea es diagnosticada como "déficit de naturaleza» (Louv, 2012); la regeneración interior para la humanidad (Berto, 2005) contemporánea enraíza en la "biofilia" (Barbiero y Berto, 2016; Barbiero, 2017). (c) La mente humana es incomprensible sin la interacción con el entorno natural; la historia de la humanización es la de una relación entre actividad exploradora y "ofrecimientos» (affordances) (Gibson, 1974) de la naturaleza ${ }^{2}$, constituyéndose en determinante de la elaboración de sentido (Norman, 2010).

El asunto por el que preguntamos destapa un aspecto peculiar del trayecto vital del género humano, cuando tuvo lugar el «acontecimiento»: la separación ecoevolutiva de los chimpancés en un período de la era terciaria llamado Oligoceno (Picq, 2016, p. 21). Podría decirse que el germen de la epopeya humana estuvo en un grupo chimpancé. Por más que la mente occidental haya ignorado al simio en el pasado: L'animal que donc Je suis (Derrida, 2008). Los simios entraron definitivamente en la escena occidental de la mano de tres mujeres, a partir de 1960: Jane Goodall investigando chimpancés (1986) ${ }^{3}$, Dian Fossey, observando gorilas (1990), y Birute Galdikas, estudiosa de los orangutanes de la Reserva Natural de Tanjung Puting. ${ }^{4}$ El primatólogo Waal (2018) nos advierte que la complejidad de la conducta chimpancé no se describe completamente mientras se evite cuidadosamente la menor alusión a sus emociones.

\subsection{El entorno académico había privilegiado la inteligencia técnica}

En el entorno académico se venía asumiendo como indicador preferente de capacidad intelectual la competencia técnica (Burke y Ornstein, 2001), el modelo tecnológico de la inteligencia (Cela Conde y Ayala, 2001), las funciones mentales humanas de "inteligencia operativa», cuya manifestación más específica es

2. "Pero dentro de cada uno de nosotros hay siempre escondido un hombre prehistórico, que aún se despierta al escuchar la llamada de la selva». (Arsuaga, 1999, p. 18).

3. Veáse: http://janegoodall.es/es/misionehistoria.html En 1967 había publicado My Friends the Wild Chimpanzees.

4. Véase: https://www.descubresinlimites.com/borneo 
la "aplicación técnica». En síntesis, la especie humana, "ha adoptado la selección técnica como mecanismo de adquisición de complejidad". (Carbonell y Sala, 2002, p. 36). Este planteamiento tiene la ventaja de poder tratar en la investigación con evidencias empíricas (fósiles y útiles), características de un Homo faber; como lo llamó Bergson (1907, p. 38).

El modelo cambia de signo por los años de 1960, cuando Goodall muestra el empleo de instrumentos por parte de los chimpancés de Gombe Stream o Toshisada Nishida en Mahale, ambos en Tanzania (Whiten y Boesch, 2001).

En este contexto, Goodall puso de relieve que la relación con la madre es fundamental para el desarrollo de la cría; su independencia se retrasa hasta los 6-9 años. De esta relación recibe la cría alimento, protección e información; puso de manifiesto la complejidad de la comunicación corporal y la importancia práctica de vocalizaciones personalizadas de proximidad y a distancia, reconocimientos e intercambios emocionales. La capacidad potencial de aprendizaje chimpancé la pusieron de relieve en 1966 el matrimonio Gardner, quienes adoptaron a la chimpancé Washoe, la cual llegó a aprender más de 250 signos, incluso enseñó algunos a otra simio también adoptada (Gardner, Gardner y Van Cantfort, 1989).

\section{IMPLICACIONES ANTROPOLÓGICAS AL MODIFICAR EL PUNTO DE VISTA SOBRE LA CULTURA}

Después de lo comentado, definimos «cultura» en un grupo animal, como el proceso interactivo social dentro del cual se reproducen, se trasmiten, comportamientos útiles (sociales o productivos). La cultura constituyó una forma de adaptación al medio, presente, entre otras especies en monos, simios, (Gómez, 2007; Goodall, 1986) y homínidos (Sabater Pi, 1992; Kawai, 1965). En todos los casos, los bebés con próximos, especialmente madres practicantes de esa competencia aprendieron y practicaron. En ninguno de los casos quedó suficientemente claro cuál fue el mecanismo de transmisión. Se indicó el aprendizaje observacional, sin la observación del modelo nunca se habría producido. También, que no se trataba propiamente de imitación; porque la imitación implica en los actores reconocimiento del otro como agente intencional; en la mera emulación el aprendiz se satisface con un resultado parecido; en esos casos, se habla de aprendizaje por «exposición social». Avital y Jablonka (2008) estiman que para algunas especies de aves y bastantes de mamíferos se han hecho imprescindibles la transferencia y el aprendizaje de información procedente de otros congéneres. Los mecanismos del aprendizaje social fueron objeto de investigación especial en Bandura (1987).

En todo caso, parece que, dentro del contexto social de muchas especies - muy en concreto, entre simios y monos-, la cría no sale adelante sin la ayuda y el cuidado de la madre y de otros congéneres; solemos denominarlo proceso de crianza. La acción de ayudar y cuidar, en origen, pudo ser tan simple como la capacidad de poder sincronizar sensaciones corporales; sincronización que se observa 
en el contagio del bostezo, el de la risa, el del llanto infantil, el del miedo y otras emociones (contagio emocional). Si el sustrato de la interacción de ayuda y cuidado es una sincronía de sensaciones y emociones, el escenario por excelencia de esa interacción es el de la relación asimétrica materno-filial que estimula un proceso de identificación o de anclaje, gancho para adoptar o emular comportamientos que ella exhibe (Waal, 2002, p. 25; 2018). Dos procesos intervienen en la emulación: la observación atenta y el ensayo; no existe recompensa durante ese tiempo, la fuerza de la identificación prevalece sobre ella. En el escenario más simple, el modelo señala el dónde actuar, allí encontraría la cría relevancia de estímulo para el cómo.

En el análisis de la ontología cultural el contexto social del aprendizaje socialmente mediado garantiza, impulsa y dirige el desarrollo. La carencia y el deterioro de una zona de acogida incondicional, idea que parcialmente se recubre con la otra de zona de desarrollo potencial, constituyen perjuicios para el despliegue de la condición humana. La participación emocional o empatía espolea la emulación y sostiene los ensayos.

\subsection{Cultura y manejo de instrumentos}

Entre las muchas cosas que aprender, un capítulo muy principal debió asociarse, desde el inicio, con el empleo de las manos, lo que anduvieron manipulando y el objetivo de la manipulación. Pero, entre la posición bípeda y la fabricación de instrumentos de piedra sabemos que pasaron millones de años.

Había existido acuerdo entre los antropólogos sobre la vinculación de instrumentos de piedra con el género Homo. Leakey y Lewin (1994) asignaron a una especie homínida el calificativo Homo habilis ("Handy man") con una antigüedad de 2,6ma. Las marcas en huesos encontrados en Dikika de 3,4ma, abrieron la posibilidad de que $A$. Afarensis también poseyera esta habilidad, antes de los 2,6ma.

Los instrumentos de piedra más antiguos encontrados hasta el momento son los de Lomekwi-3 (Turkana-Kenia); fueron descubiertos por el equipo dirigido por Lewis y Harmand y hechos públicos en Nature en mayo de 2015: yunques, núcleos y lascas, que pudieron datarse en 3.3ma. Entre 2011 y 2012 el equipo de Harmand encontró in situ 149 artefactos en superficie; en 2014-2015, 16 artefactos más a profundidad, los cuales fueron datados con la misma antigüedad.

La práctica efectiva de esta habilidad manipulativa parece demostrar que el autor: a) poseía capacidad para la selección de la materia prima; b) comprendía por experiencia la mecánica de la fractura y la posición favorable para golpear; c) era capaz de controlar el movimiento de golpeo y la fuerza percutora sobre el bloque seleccionado; d) competencia viso-espacial para comprender el ángulo con el que incidir y cómo situar y mantener el bloque que permita desprendimiento de lasca (Lewis y Harmand, 2016).

El 19 de julio del 2001 el equipo de Brunet había descubierto el cráneo incompleto de Toumai, junto a él fueron apareciendo restos fósiles de al menos 
12 individuos; las primeras dataciones se acercan a los $7 \mathrm{ma}$ y la convicción acerca de "puede considerarse el homínido más antiguo conocido". (Brunet, 2006, p. 192). Toumai, catalogado como Sabelantropus tchadensis, pudo tener una estatura, entre $1,20 \mathrm{~cm}$ y $1,30 \mathrm{~cm}$; la capacidad craneana de unos $350-380 \mathrm{~cm}^{3}$; el agujero occipital, foramen magno, comparte su posición con bípedos más recientes. Para el equipo de Brunet: el primer homínido.

Durante algunos millones de años estos homínidos fueron de baja estatura, cerebros de tamaño próximo al chimpancé, pero sorprendentemente terminaron extendiéndose por un territorio enorme, con variaciones ecológicas notables y fuentes diferentes de recursos alimentarios. Del árbol de especies que practicaron la postura bípeda al principio, se dice que "su mente aún era la de un mono, la de un antropomorfo como los actuales chimpancés [...] no eran aún humanos». (Arsuaga, 1999, p. 36). Picq declara que, durante millones de años, aquellos homininos adquirieron aptitudes de acceso y recolección de alimentos, "difíciles de conseguir sin útiles, técnicas y aprendizajes». (2016, p. 201); las crías debieron aprender observando a sus madres, ensayando sin éxito durante años, bajo la atenta mirada de la madre y con sistemas de comunicación precarios: variedad de gritos y de vocalizaciones; gran variedad de gestos y actitudes corporales, relacionados con una gran riqueza de comportamientos sociales: fueron el objeto de tradiciones y culturas diferentes, "transmitidas principalmente por las hembras». (Picq, 2016, p. 202).

Todos los indicios apuntan a que en el origen predominó la precariedad, la vulnerabilidad y la dependencia necesitante de cooperación cuidado, a la que corresponden actitudes de disposición a la ayuda, soldadas por apego emocional; con comunicación, pero sin lenguaje. Otros autores añaden carácter acumulativo que favorecía, por un efecto trinquete (Tomasello, 1999) y otras complejidades mentales (Lisón, 2005, p. 7). Pero, es habitual tomar la cultura en un estado de evolución muy avanzado; que supone el lenguaje como la mediación clave en los procesos de transmisión. Nosotros ampliamos el espacio de los procesos mediadores.

\section{LA CLAVE QUE FINALMENTE ADOPTAMOS}

Mahner y Bunge (2000), teóricos de la sociobiología, advierten de que ni los procesos ni los mecanismos se pueden tomar como primitivos en una ontología. La posición primaria la poseen las cosas que cambian. En la evolución cultural del género humano, el proceso de humanización tomó comienzo en una complicada ramificación con especies hoy extintas. Tuvieron lugar transformaciones cualitativas en los organismos, variaciones en el modelo de desarrollo, adquirieron y/o perdieron propiedades; también debieron aparecer propiedades que saltan a un espacio diferente de estados (Mahner y Bunge, 2000).

Hoy nos sorprende la complejidad del comportamiento de los primates, al observarlos en sus hábitats naturales, como describieron las investigadoras pioneras ya citadas (Fossey, 1990; Goodall, 2005; Varios, 2019; Galdikas, 2013) y asombran las 
actuaciones de otras especies, de las cuales resaltaremos aquí solo dos: los elefantes (Moss, 1992; Safina, 2017) y los cefalópodos (Godfrey-Smith, 2017). También nos sorprende el parentesco entre la afectividad de los primates y la de los seres humanos y la conexión mediante mecanismos empáticos con los grupos de primates observados (Waal, 2018, p. 9).

La transmisión cultural observada en muchas especies animales justificó en ellas la investigación sobre las vías extragenéticas de reproducción de comportamientos, con mecanismos de complejidad diferente: simple remedo o copia, imitación propiamente dicha, enseñanza con mediación semiótica corporal, enseñanza con mediador lingüístico, enseñanza mediada por instrumentos.

Sin embargo, el significado dominante del término cultura se centró en el contenido de lo que se transmite, criterio que comenzó en el siglo XIX y culminó con la obra de Tylor Cultura primitiva (1977) (Goberna Falque, 2003).

Un fuerte movimiento antropológico está reponiendo, en la actualidad, los mecanismos de transmisión como clave del significado de cultura, aunque llevar el criterio a los inicios de la hominización presente dificultades extremas de análisis y únicamente se puedan aplicar pruebas indirectas.

\subsection{Un cambio decisivo en la humanización estuvo en la evolución de los meca- nismos de transmisión cultural}

Existe hoy la convicción, cada vez de más autores, sobre que la educación (ellos emplean el término cultura) fue factor de transformación evolutiva. Esta emergencia evolutiva de mecanismos de transmisión cultural, "fue un ingrediente esencial tanto para nuestro éxito ecológico como para nuestra capacidad de cooperación. No fue el único, pero sí fundamental». (Boyd, 2018, p. 126).

Permanece amplio consenso sobre el alto nivel de adaptación cultural que implica la elaboración de artefactos. El grupo de «los fabricantes de hachas» (Burke y Ornstein, 2001) había ampliado las redes de parentesco, se había expandido por un territorio enorme, ampliaron sus fuentes de alimento, incluyendo con toda probabilidad la carne y la médula. La diversificación de la actividad exploratoria por territorios ecológicamente diferentes hace pensar en un complejo mapa cognitivo. Los hombres aprendieron a compartir la proteína encontrada. "Las mujeres de mediana edad se especializan en el cuidado de los niños, el procesado de alimentos, la producción de artesanía y otras tareas esenciales». (Boyd, 2018, p. 73).

Nos interesa resaltar y parece razonable, que en el grupo de los fabricantes de hachas, en torno a 3-4ma debió desarrollarse la cooperación en muchas actividades, en la producción intencional de artefactos y en la crianza compartida o participada. Si fueron capaces, ellos y ellas, de imaginar mentalmente el proceso de manipulación artesana, los adolescentes también habrían desarrollado la capacidad intencional de imitación; los adultos advierten que los aprendices no saben y los aprendices 
aprenden dónde y qué mirar practicando la atención conjunta. En esos grupos de incipientes artesanos, hábiles recolectores y rastreadores, las mujeres cooperadoras debieron ser las primeras en proporcionar ayuda a niños y adolescentes en vistas a mejorar sus prácticas.

Creemos que el proceso de adaptación cultural incluye la competencia de imitación y patrones de comportamiento intencional de ayuda en el modelo; es decir, la adaptación cultural aplicable a la producción de artefactos, debió evolucionar a partir de la gestión cultural recolectora compartida de entornos diferentes; así pudieron ir formando parte de los patrones sociales el aprendizaje cultural, que desarrolle la imitación y formas de protoenseñanza. La mediación comunicativa mínima pudo ser la que denominamos comunicación corporal mediante indicios sensoriales, en los que se fundamenta la seña.

El primer obrador de la piedra, debió ser precedido de un largo período de producción y empleo de útiles perecederos, que ayudarían en la asociación entre la recolección y la crianza, donde pudo evolucionar la imitación. La imitación con fidelidad requiere de inteligencia social considerable, buena percepción de las pistas sutiles y la resolución de difíciles problemas de decisión en la acción (Orr, 2018, p. 135).

Lo que no suele comentarse es que el escenario de transmisión cultural con imitación intencional es bifocal: conlleva exhibición intencionada para que el aprendiz incremente la fidelidad de la copia. Esto parece un proceso de imitación favorecido con ayuda del modelo. La construcción intencional de artefactos, creemos que nace en un contexto de patrones mentales entre los que ya figuraba cooperación social, ayuda mutua, explotación de nuevos entornos ecológicamente diferenciados y donde el éxito vital implicaba la cooperación en la crianza. Antes que cazadores estos grupos en proceso de humanización eran presas potenciales; sobrevivieron los que evolucionaron defendiendo su vulnerabilidad con iniciativas culturales. En la iniciativa cultural no solamente hay exigencia mental para la imitación, también para la percepción del estado necesitante de ayuda; esa percepción de la necesidad de ayuda es la que reclama la respuesta de "enseñanza", la cual, en principio, no requiere del lenguaje, como se puede observar durante la crianza, antes de que el niño aprenda a hablar. En la actualidad, sobre todo ese proceso recae la palabra educación.

Nuestra deliberación ha intentado reconstruir un escenario evolutivo; en el fondo, se trata de un relato que intenta encajar todas las piezas de información obtenidas de las investigaciones comunicadas. La verosimilitud de este tipo de relato depende de la comprensión y aceptación de los datos con que se construye. Creemos que el proceso de enseñanza-aprendizaje coevolucionó desde el principio de la humanización. Creemos que el relato puede contarse como la evolución del proceso educativo. 
JOAQUÍN GARCÍA CARRASCO Y MACARENA DONOSO GONZÁLEZ LA EDUCACIÓN SE INCRUSTÓ EN EL PROCESO EVOLUTIVO Y FLORECIERON LOS HUMANOS

\section{REFERENCIAS BIBLIOGRÁFICAS}

Aldovasio, J. M. (2008). El sexo invisible: una nueva mirada a la historia de las mujeres. Lumen. Ardrey, R. (1998). La evolución del hombre: La hipótesis del cazador. Alianza Editorial.

Arsuaga, J. L. (1998). La especie elegida: La larga marcha de la evolución humana. Ediciones Temas de Hoy.

Arsuaga, J. L. (1999). El collar del neandertal: En busca de los primeros pensadores. Ediciones Temas de Hoy.

Arsuaga, J. L. (2001). El enigma de la esfinge: Las causas, el curso y el propósito de la evolución. Plaza y Janés Editores.

Arsuaga, J. L. (2019). Vida, la gran historia: un viaje por el laberinto de la evolución. Planeta.

Arsuaga, J. L. y Martín-Loeches, M. (2013). El sello indeleble. Pasado, presente y futuro del ser humano. Debate.

Avital, E. y Jablonka, E. (2008). Animals Traditions: Behavioral Inheritance in Evolution. Cambridge University Press.

Bandura, A. (1987). Teoría del aprendizaje social. Espasa-Calpe.

Barbiero, G. (2017). Ecologia affettiva. Come trarre benessere físico e mentale dal contatto con la Natura. Mondadori.

Barbiero, G. y Berto, R. (2016). Introduzione a la Biofilia: La relazione con la Natura tra genética e psicología. Carocci Editore.

Bartra, R. (1996). El salvaje en el espejo. Destino.

Bartra, R. (2012). El mito del salvaje. Fondo de Cultura Económica.

Bergson, H. (1907). La evolución creadora. Espasa-Calpe.

Berto, R. (2005). Exposure to Restorative Environments Helps Restore the Attentional Capacity. Journal of Environmental Psychology, 25(3), 249-259. https://doi.org/10.1016/j. jenvp.2005.07.001

Boyd, R. (2018). Un animal diferente: cómo la cultura transformó nuestras especies. Ediciones Oberon.

Brunet, M. (2006). D'Abel à Toumaï: Nomade, chercheur d'os. Odile Jacob.

Bunge, M. (2004). Emergencia y convergencia: novedad cualitativa y unidad del conocimiento. Gedisa.

Burke, J. y Ornstein, R. (2001). Del hacha al chip: cómo la tecnología cambia nuestras mentes. Planeta Libros.

Carbonell, E. y Sala, R. (2002). Aún no somos humanos. Propuestas de humanización para el tercer milenio. Península.

Carrithers, M. (1995). ¿Por qué los humanos tenemos culturas? Alianza.

Cela Conde, C. y Ayala, F. (2001). Senderos de la evolución humana. Alianza.

Colom, A. J. (2005). Antropología y antropologías de la educación (Una revisión). En C. Lisón (Ed.), Antropología: Horizontes educativos (p.37-57). Universidad de Granada.

Dennett, D. (2000). Tipos de mente: hacia una comprensión de la conciencia. Debate.

Derrida, J. (2008). L'Animal que donc je suis. Éditions Galilée.

Doval Salgado, L. (1979). Acercamiento etimológico al término «Educación». Revista Española de Pedagogía, 37(146), 115-121. 
Dunbar, R. (2007). La Odisea de la bumanidad: Una nueva bistoria de la evolución de la raza humana. Drakontos.

Fossey, D. (1990). Gorilas en la niebla. Salvat.

Galdikas, B. (2013). Reflejos del Eden. Mis años con los orangutanes de Borneo. Pepitas de Calabaza.

García-Carrasco, J. (2007). Leer en la cara y en el mundo. Herder.

García-Carrasco, J. y Canal, R. (2018). Así somos los humanos: Plásticos, vulnerables y resilientes. FahrenHouse.

Gardner, R. A., Gardner, B. T. y Van Cantfort, T. E. (1989). Teaching Sing Language to Chimpanzees. State University of New York Press.

Gazzaniga, M. (2010). ¿Qué nos hace bumanos?: La explicación científica de nuestra singularidad como especie. Paidós.

Gibson, J. J. (1974). La percepción del mundo visual. Editorial Infinito.

Goberna Falque, J. R. (2003). "What's Culture»: cien años de controversias en antropología sajona (1871-1971). Gallaecia: revista de arqueoloxía e antigüidade, (22), 531-554. https://dialnet.unirioja.es/servlet/articulo?codigo $=633501$

Godfrey-Smith, P. (2017). Otras mentes. El pulpo, el mar y los orígenes profundos de la consciencia. Taurus.

Golding, W. (1996). El señor de las moscas. Alianza.

Gómez, J. C. (2007). El desarrollo de la mente en los simios, los monos y los niños. Morata.

Goodall, J. (1967). My Friends the Wild Chipanzees. National Geographic Society.

Goodall, J. (1986). En la senda del hombre: vida y costumbres de los chimpancés. Salvat.

Goodall, J. (1986). The Chimpanzees of Gombe: Patterns of Behabior. Harvard University Press.

Goodall, J. (2005). Existo, luego pienso: Los primates y la evolución de la inteligencia humana. Ateles Editores.

Gould, S. J. (1994). Ocho cerditos. "De neumáticos a sandalias". Crítica.

Gould, S. J. (2012). La estructura de la Teoría de la Evolución. El gran debate de las ciencias de la vida. Tusquets.

Herbart, J. F. (1983). Pedagogía general derivada del fin de la educación. Humánitas.

Kandel, E. (2019). La nueva biología de la mente: qué nos dicen los trastornos cerebrales sobre nosotros mismos. Paidós.

Kardiner, A. (1955). Fronteras psicológicas de la Sociedad. Fondo de Cultura Económica.

Kawai, M. (1965). Newly acquired precultural behavior of the natural troop of Japanese monkeys on Koshima Islet. Primates, 6(1),1-30. https://doi.org/10.1007/BF01794457

Laland, K. (2017). Darwin's Unfinised Symphony. How Culture made Human Mind. Princeton University Press. https://doi.org/10.1515/9781400884872

Laland, K. (2018). La evolución de nuestra excepcionalidad. Investigación y Ciencia, 506, 1-19. Leakey, R. y Lewin, R. (1994). Nuestros orígenes. En busca de lo que nos hace humanos. RBA.

Lerena, C. (1983). Reprimir y liberar: crítica sociológica de la educación y la cultura contemporánea. Akal.

Lewis, J. E. y Harmand, S. (2016). An earlier origin for stone tool making: implications for cognitive evolution and the transition to Homo. Philosofical Transactions of the Royal Society, 371, 1-8. https://doi.org/10.1098/rstb.2015.0233 
JOAQUÍN GARCÍA CARRASCO Y MACARENA DONOSO GONZÁLEZ LA EDUCACIÓN SE INCRUSTÓ EN EL PROCESO EVOLUTIVO Y FLORECIERON LOS HUMANOS

Lisón, C. (2005). Antropología: Horizontes educativos. Universidad de Granada.

Lorenz, K. (1982). Sobre la agresión: el pretendido mal. Siglo XXI.

Louv, R. (2012). Volver a la Naturaleza. Editorial Integral.

Martínez Pulido, C. (2012). La senda mutilada: la evolución bumana en femenino. MinervaBiblioteca.

Martínez Pulido, C. (2018). El papel de las mujeres en la evolución humana. Santillana.

Mahner, M. y Bunge, M. (2000). Fundamentos de biofilosofía. Siglo XXI.

Maturana, H. (1995). La realidad ¿objetiva o construida? (T.1). Fundamentos biológicos de la realidad. Barcelona.

McLuhan, M. (1996). Comprender los medios de comunicación: las extensiones del ser humano. Paidós.

McLuhan, M. y Fiore, Q. (1969). El medio es el masaje: un inventario de efectos. Paidós.

Mithen, S. (1998). Arqueología de la mente: orígenes del arte, de la religión y de la ciencia. Crítica.

Montagu, A. (1972). La humanización del hombre. Tiempo Nuevo.

Montessori, M. (1921). Antropología pedagógica. Casa Editorial Araluce.

Mosterín. J. (2009). La cultura humana. Espasa.

Moss, C. (1992). Los elefantes. Plaza y Janés.

Norman, D. A. (2010). La psicología de los objetos cotidianos. Nerea.

Orr, H. A. (2018). La importancia del aprendizaje cultural. En R. Boyd (Ed.), Un animal diferente (pp.131-140). Ediciones Oberon.

Piaget, J. (1986). Epistemología genética. Debate.

Piaget, J. (2012). La equilibración de las estructuras cognitivas: Problema central del desarrollo. Siglo XXI.

Picq, P. (2016). Premiers hommes. Flammarion.

Robins, W. J (2003). Un paseo por la antropología educativa. Nueva Antropología, 19(62), 11-28. http://www.scielo.org.mx/pdf/na/v19n62/v19n62a2.pdf

Rodríguez Shadow, M. y Campos Rodríguez L. (2010). Los aportes femeninos a la Antropología Social: Las Pioneras. Investigación y Ciencia, (46), 36-42.

Rosenstiel, A. (1977). Education and Anthropology: An Annotated Bibliography. Garland Reference Library of Social Science.

Sabater Pi, J. (1992). El chimpancé y los orígenes de la cultura. Anthropos.

Safina, C. (2017). Mentes maravillosas: Lo que piensan y sienten los animales. Galaxia Gutemberg.

Sánchez Ron, J. M. (2011). La nueva ilustración: Ciencia, Tecnología y Humanidades en un mundo interdisciplinar. Ediciones Nobel.

Sánchez Tortosa, J. (2018). El culto pedagógico: crítica del populismo educativo. Akal.

Shannon, C. (1948). A Mathematical Theory of Communication. http://people.math.harvard. edu/ ctm/home/text/others/shannon/entropy/entropy.pdf

Simondon, G. (2007). El modo de existencia de los objetos técnicos. Prometeo Libros.

Spindler, G. (Ed.) (1955). Education and anthropology. Stanford University Press.

Tattersall, I. (1998). Hacia el ser humano: la singularidad del hombre y la evolución. Península. 
Tomasello, M. (1999). The human adaptation for culture. Annual Review of Anthropology, 28, 509-529. https://doi.org/10.1146/annurev.anthro.28.1.509

Tomasello, M. (2007). Los orígenes culturales de la cognición bumana. Amorrortu.

Tylor, E. B. (1977). Cultura primitiva. Los origenes de la cultura (T.I.). Ayuso.

Varios. (2019). Jane Goodall: Una vida dedicada al estudio de los chimpancés salvajes de Africa. Natgeo-Ciencias RBA.

Vygostki, L. S. (2012). El desarrollo de los procesos psicológicos superiores. Planeta.

Waal, F. de (2002). El simio y el aprendiz de sushi: Reflexiones de un primatólogo sobre la cultura. Paidós Ibérica.

Waal, F. de (2018). La dernière étreinte: Le monde fabuleux des émotions animales...et ce qu'il révèle de nous. Les liens qui Libèrent.

Wenger, E. (2001). Comunidades de práctica: aprendizaje, significado e identidad. Paidós Ibérica.

Whiten, A. y Boesch, C. (2001). Expresiones culturales de los chimpancés. Investigación y Ciencia, (294), 28-35.

Willians, R. (2003). Palabras Clave: un vocabulario de la Cultura y la Sociedad. Nueva Visión. 